\title{
E quando o ‘lugar’ é a metrópole? Pesquisa e ensino de Geografia no contexto metropolitano de Porto Alegre
}

Ana Clara Fernandes*

\section{Problema de pesquisa}

A necessidade de relacionar os estudos de Geografia da Educação Básica com o cotidiano dos alunos é tema discutido por vários autores já há algumas décadas. Ao problematizar sobre os estudos geográficos na França dos anos 1970 do século XX, Lacoste (1988) argumenta em A Geografia - Isso serve, em primeiro lugar, para fazer a guerra sobre a importância de atividades pedagógicas nas aulas de Geografia que possibilitem aprender a ler o espaço vivido (a carta) como contraposição à postura ideológica de negar esse conhecimento aos cidadãos em prol dos interesses das classes dominantes:

Por que não aprender a esboçar o plano da aldeia ou do bairro? Por que não representar sobre o plano de sua cidade os diferentes bairros que conhecem, aquele onde vivem, aquele onde os pais das crianças vão trabalhar, etc.? Por que não aprender a se orientar, a passear na floresta, na montanha, a escolher determinado itinerário para evitar uma rodovia que está congestionada? (LACOSTE, 1988, p. 25)

No Brasil, os Parâmetros Curriculares Nacionais, elaborados nos anos 1990, ainda hoje vigentes, colocam como central a contribuição da Geografia para a compreensão do espaço vivido em todas as séries da Educação Básica. Nas séries finais do Ensino

* Professora de Geografia do Ensino Médio do Colégio de Aplicação da Universidade Federal do Rio Grande do Sul - CAp/UFRGS. Doutoranda em Geografia pela UFRGS. E-mail: clarageol8@gmail.com 
Fundamental é de suma importância "[...] que o espaço vivido pelos alunos continue sendo o ponto de partida dos estudos ao longo do terceiro e quarto ciclos e que esse estudo permita compreender como o local, o regional e o global relacionam-se nesse espaço" (PCNs, p. 30). No Ensino Médio, "entendemos que, ao se identificar com seu lugar no mundo, ou seja, o espaço de sua vida cotidiana, o aluno pode estabelecer comparaçôes, perceber impasses, contradiçôes e desafios do nível local ao global" (PCNs, p. 311).

Essas questões permanecem na literatura mais recente. Em artigo publicado na revista Terra Livre $n^{0} 16$, Callai (2001) problematiza o ensino da Geografia em um contexto social de grandes mudanças, no qual a instrumentalização para exercício da cidadania é uma de suas tarefas. Para tanto, salienta que "[... o estudo do local onde vivem (os alunos) se torna fundamental, ao mesmo tempo em que é um importante exercício para entender o mundo da vida” (CALLAI, 2001, p. 147).

Questionamos, então, o que é o "local" ou o "lugar" de onde, como nos apontam as referências acima, deveríamos realizar em sala de aula os estudos de Geografia; como definir o "local" ou o "lugar" em um contexto metropolitano?

Callai propõe que o município, enquanto unidade administrativa "significativa para grande parcela da população brasileira”, represente o estudo do local, do lugar. Ao mesmo tempo, relativiza esta possibilidade: “[...] poderá ser um bairro, uma comunidade, assim como poderá ser uma pequena (em extensão) região que agrupe alguns municípios” (ibid., p. 148).

Os questionamentos de Pontuschka (2002) sobre as escalas de análise do espaço geográfico, seu conteúdo cada vez mais complexo e as proposiçôes para abordá-lo em sala de aula trazem também contribuição importante para pensarmos nossa prática. Segundo esse autor:

Diante das múltiplas ações e orientações originárias dos órgãos centrais da educação vinculadas à política educacional do país, perguntamos: que caminhos o professor e a escola podem trilhar para que os alunos 
dos diferentes níveis de ensino compreendam o espaço geográfico e ampliem sua visão de mundo, conheçam o seu papel na sociedade moderna ou pós-moderna, como querem alguns, em uma economia mundializada e de vida globalizada? Como a globalização se traduz no espaço de vida do professor e do aluno? Como, do ponto de vista do espaço geográfico, integrar a escala internacional (globalização) à escala local (espaço vivencial)? Não existem respostas mágicas para essas questôes [...] (PONTUSCHKA, 2002, p. 111).

A complexidade territorial e social das grandes aglomerações urbanas é um desafio para ensinar e para aprender Geografia. A globalização e, especialmente, o crescente acesso às novas tecnologias de informação agregam novas dimensões ao espaço vivido. Essas dimensões não anulam sua importância, ao contrário, reforçam suas múltiplas possibilidades. Nesse sentido, o cotidiano tecnológico e informacional a que têm acesso nossos alunos não anula a necessidade de estudar a concretude do "lugar”, ao contrário, pode enriquecer seu estudo e torná-lo mais atrativo. Nas questões colocadas por Pontuschka (2002), podemos acrescentar que considerar o espaço vivencial é também lidar com a mobilidade: a possibilidade de morar, estudar e trabalhar em bairros distintos, distantes, em outra cidade. A nossa experiência em escolas públicas, localizadas em Porto Alegre, demonstra que os alunos são oriundos de diferentes bairros e também de outros municípios ${ }^{1}$. Com o intuito de contribuir para romper com a "ausência do lugar" nas aulas de Geografia a partir do terceiro ciclo da Educação Básica, e com a certeza de que não esgotaremos a questão, nossa pesquisa procura responder ao seguinte questionamento: Como realizar, na metrópole, o estudo do "lugar", nas aulas de Geografia, a partir do terceiro ciclo da Educação Básica?

1 Situação também vivida com os alunos da Educação Básica do Colégio de Aplicação da UFRGS. 


\section{Justificativa}

Ao trabalhar com o espaço vivido em uma turma de trinta alunos, deparamo-nos com o fato de que ele não é único, que necessariamente não está em uma mesma delimitação, em um mesmo bairro, não agrega as mesmas dimensões. Uma forma de lidar com essa situação é propor que o espaço vivido seja o entorno da escola, suas proximidades, o bairro onde ela se localiza. Em um primeiro momento de análise, considerar o bairro da escola pode ser um exercício suficiente, mas na medida em que ampliamos e conectamos diferentes escalas para estudar/compreender o lugar onde vivemos, é necessário incluir e articular outros trajetos e vivências. Sem isso, corremos o indesejado risco de tornar nosso discurso vazio, com um amontoado de informaçóes desconectadas, e as aulas um pouco do que descreve Monbeig (1954, p.1): "[...] listas indigestas de nomes de lugares ou dados numéricos, liçôes atrozes que somente os menos inteligentes e os mais obstinados de nossos condiscípulos chegavam a recitar razoavelmente".

Ao agregar os diferentes percursos e vivências dos alunos, teremos certamente a descrição de vários fragmentos de um mesmo lugar - a metrópole e seu entorno. As diferenças em um primeiro momento irão demonstrar a heterogeneidade do lugar (descrição de várias paisagens e dimensões) e, após, as diferentes análises abrem a possibilidade de entender sua complexidade.

Resgatando novamente nossa experiência em escolas públicas de Porto Alegre e também de Gravataí, podemos dizer que o estudo do espaço geográfico Região Metropolitana de Porto Alegre, onde está inserida a delimitação que fizemos para definir o "lugar", é praticamente inexistente. Existe um projeto de popularização do ensino da Região Metropolitana de Porto Alegre no Colégio de Aplicação - UFRGS que visa a aproximar principalmente a produção acadêmica do universo escolar nas aulas de Geografia urbana. Além dessa iniciativa, os professores que abordam seu estudo em sala de aula o fazem de maneira provavelmente solitária. As pesquisas e informaçôes estão limitadas 
a órgãos administrativos e de pesquisa como a Fundação de Economia e Estatística do Rio Grande do Sul, a Metroplan, a Universidade, o Instituto Brasileiro de Geografia e Estatística sem que sua sistematização e socialização sejam efetivas no ensino de Geografia.

\section{Objetivos}

O objetivo central de nossa pesquisa é construir e sistematizar possibilidades de ensino e de aprendizagem do saber geográfico em sala de aula a partir do lugar, Porto Alegre e seu entorno, com uma abordagem que leve em consideração seus conteúdos sociais e naturais e que privilegie a vivência cotidiana dos alunos. Para tanto, elencamos alguns objetivos específicos que esperamos alcançar durante o desenvolvimento da pesquisa:

- Tornar disponíveis e compreensíveis informações e estudos sobre Porto Alegre e seu entorno (RMPA) na sala de aula - socialização do conhecimento.

- Oportunizar e estimular nas aulas de Geografia uma aprendizagem em que os alunos se percebam como possíveis integrantes e atuantes dos processos de transformação do lugar onde vivem - construção da cidadania.

- Propor, experimentar e avaliar a referência do lugar como ponto de conexão das diferentes escalas de análise para estudar e aprender Geografia a partir do terceiro ciclo da Educação Básica - metodologia de ensino e aprendizagem.

Ao final da pesquisa temos por meta divulgar a experiência com o intuito de socializar, debater e contribuir para o enriquecimento de nossas práticas, saberes e fazeres geográficos. Para tanto, o produto final se desenhará na forma de um Projeto de Extensão que contemple o tema de nossa pesquisa, intitulado "E quando o lugar é a metrópole?" voltado para a comunidade e, especialmente, para os professores de Geografia. 


\section{Metodologia}

Toda leitura geográfica do espaço é precedida de uma leitura anterior do espaço vivenciado ${ }^{2}$.

Como primeira referência para pensar o lugar, resgatamos as considerações finais de Santos (2008, p. 339), em A natureza do espaço: "[...] cada lugar é, ao mesmo tempo, objeto de uma razão global e de uma razão local, convivendo dialeticamente". Ou seja, o lugar vivenciado, sua materialidade, expressa lógicas nem sempre convergentes. O lugar é local de conflito expresso ou latente. O lugar que delimitamos (Porto Alegre e seu entorno) como outros lugares onde se reproduz a sociedade urbana é uma criação humana, o lugar de reprodução do capital e da humanidade. Conforme Park (1976, p. 26), "[...] a cidade é algo mais do que um amontoado de homens individuais e de conveniências sociais, ruas, edifícios, luz elétrica, linhas de bonde, telefones etc.; algo mais também do que uma mera constelação de instituições e dispositivos administrativos". Com essa perspectiva, estudaremos o lugar enquanto: (1) o ambiente/habitat da parcela da humanidade que ali está, onde estão colocadas/ imbricadas dimensões sociais e naturais; (2) um local/global de onde podemos compreender o espaço geográfico.

Com esta abordagem, a metodologia que se pretende em sala de aula pode ser exemplificada com a seguinte situação:

- Em determinado momento das atividades em sala de aula, é solicitado aos alunos que representem a cidade através de um croqui no qual os diferentes usos do solo sejam agrupados (regionalizados). Não é necessário aqui considerar outros aspectos cartográficos além da legenda,

2 Paráfrase de FREIRE (2001, p. 63), em entrevista concedida à revista italiana Terra Nuova: "Insistir em que toda leitura da palavra é sempre precedida de uma certa leitura do mundo talvez seja a melhor maneira de começar a tratar a questáo que você me coloca”. 
da orientação e da visão vertical. Em determinado momento da atividade, um aluno questiona como seria desenhar uma fruta vista de cima, "[...] não tem como desenhar uma fruta vista de cima". O professor problematiza a questão: "[...] por que não?”; "[...] como seria uma fruta vista de cima?”. Outro aluno argumenta então: “[...] o que fruta tem a ver com Geografia?”. A escuta por parte do professor dessas questóes, aparentemente desconectadas com a proposta inicial da atividade, pode ser extremamente significativa para o estudo do lugar na perspectiva de que ele é local/global. Primeiro, é importante encorajá-los a desenhar uma fruta vista de cima. Depois, é importante responder o que fruta tem a ver com a Geografia, porque, por meio de tal resposta, um leque de possibilidades se abrirá para se trabalhar a categoria inicial que havia sido proposta (região) em outras escalas. Isso pode ser feito com o auxílio de um eficiente atlas ou com a consulta a sites que contenham dados e mapas da produção agropecuária no Brasil (comércio interno) e em outros países (comércio internacional). Podem-se chegar, a partir disso, na divisão internacional do trabalho, nas zonas térmicas da Terra, nos diferentes tipos de solo, de climas, entre outros. A dimensão da natureza no habitat humano pode ser também trabalhada no "lugar": que frutas são cultivadas em Porto Alegre? Onde? Por que são essas e não outras frutas? Que frutas existiam em Porto Alegre antes da ocupação humana? Como era a paisagem antes do cultivo das frutas? Que combinação de elementos naturais é necessária para seu cultivo? Elas poderiam ser cultivadas em outro lugar? Além disso, obviamente, questionamentos relativos à divisão do trabalho, expressa pelas atividades exercidas em cada parte da cidade, de sua heterogeneidade, poderiam surgir. A partir dos estudos realizados em aula, pode-se elaborar um roteiro de campo em que alguns dos pontos trabalhados serão observados e anotados para serem novamente 
retomados em aula. Dessas anotações, novas questões poderão surgir e outras atividades poderão ser planejadas.

A metodologia inclui também possibilidade de atividades interdisciplinares que serão organizadas de acordo com a disponibilidade e interesse dos colegas da área de Ciências Humanas, de Língua Portuguesa e de outras áreas. As atividades com outras áreas de conhecimento poderão ser desenvolvidas com:

- os professores de Línguas Estrangeiras: confecção de textos bilíngues;

- os professores de Língua Portuguesa e de Literatura: produções textuais, poesias elaboradas pelos alunos e leitura e interpretação de textos, poesias, reportagens jornalísticas;

- os professores de Teatro e de Música: conforme a escolha dos grupos na elaboração das sínteses dos temas trabalhados;

- os professores de Matemática e Artes: nas representações cartográficas, tabelas, gráficos;

- as demais possibilidades que surgirem para o trabalho interdisciplinar durante o desenvolvimento da pesquisa.

\section{Resultados e Impactos Esperados}

Os resultados e os impactos que se esperam com essa pesquisa podem ser divididos em três dimensốes:

- Na sala de aula, espera-se contribuir para que o aprendizado seja significativo para os alunos; que eles reconheçam seu cotidiano nos temas trabalhados e na sua relação com as diferentes escalas geográficas.

- Como pesquisadora, espera-se que os objetivos elencados anteriormente sejam atingidos e que eles contribuam para aproximar a ciência do ensino.

- Como professora, espera-se que as propostas possam ser socializadas e debatidas com outros professores também empenhados em (re)significar o "conteúdo escolar"; e que o ensino de 
Geografia contribua para se pensar o "lugar" a partir de diferentes possibilidades de "ser" e de "fazer".

\section{Referências}

BRASIL. Secretaria de Educação Fundamental. Parâmetros Curriculares Nacionais: geografia. Brasília: MEC/SEF, 1998.

BRASIL. Ministério da Educação. Secretaria de Educação Média e Tecnológica. Parâmetros Curriculares Nacionais: ensino médio. Brasília: MEC/SEMT, 1999.

CALLAI, Helena Copetti. A geografia e a escola: muda a geografia? Muda o ensino? In: Terra livre, n. 16, 2001. p. 133-151.

FERNANDES, Ana Clara. A cidade esparramada: considerações sobre a produção do espaço urbano-industrial em Gravataí - Região Metropolitana de Porto Alegre (RS). 2008. 182 fls. Dissertação (Mestrado em Geografia) - Universidade Federal do Rio Grande do Sul. Instituto de Geociências. Programa de Pós-Graduação em Geografia, Porto Alegre, RS.

FREIRE, Paulo. A educação na cidade. São Paulo: Editora Cortez, 2000.

LACOSTE, Yves. A geografia: isso serve, em primeiro lugar, para fazer a guerra. Disponível em: <www.scribd.com/doc/4799781/geografiayveslacoste>. Acesso em: 08 jan. 2010.

MONBEIG, Pierre. O papel e o valor do ensino de geografia. In: VESENTINI, José William. Ensino da geografia. Disponível em: <www. geocrítica.com.br>. Acesso em: 10 out 2010.

PARK, Robert Ezra. In: VELHO, Otávio Guilherme (Org.). O fenômeno urbano. 3. ed. Rio de Janeiro: Zahar, 1976. p. 26-67.

PONTUSCHKA, Nídia Nacib. A geografia: pesquisa e ensino. In: CARLOS, Ana Fanni Alessandri (Org.). Novos caminhos da geografia. São Paulo: Contexto, 2002. p. 111-142.

SANTOS, Milton. A natureza do espaço: técnica e tempo; razão e emoção. São Paulo: Editora da Universidade de São Paulo (Coleção Milton Santos; 1). 4. ed., $4^{\mathrm{a}}$ reimpressão, 2008. 